\title{
Low-Carbon Policy Making vs. Low-Carbon Policy Modelling: State-of-the-Art and Challenges
}

\author{
Frédéric Ghersi
}

CNRS, CIRED, 45 bis, avenue de la Belle Gabrielle, 94736 Nogent sur Marne CEDEX, France.

Phone +33143947373

Fax +33143947370

e-mail: ghersi@centre-cired.fr

\section{Abstract}

This paper surveys the use made of modelling expertise in the recent literature focused on the policymaking of low-carbon societies in Europe, both peerreviewed and 'grey'. The first section focuses on the prominent policy instrument of carbon pricing. It starts by analysing the somewhat confusing use made of carbon pricing modelling in policy reports emanating from the French and British governments, then reviews some modelling results on carbon pricing in a 'second best' world. The second section lists the impressive collection of more focused policy instruments that are advocated in both governmental and non-governmental literature. It insists on the contrast between the high degree of precision of some of these policy proposals, and the limited modelling of their impacts, either from an environmental or an economic point of view. The third section concludes on recommendations to the policy modelling community inspired by this survey. Purposely avoiding the current controversies surrounding cost-benefit analysis, it advocates further applied research on the cost-efficiency of carbon pricing trajectories (when flexibility); on the terra incognita beyond first best uniform pricing (where flexibility); on the elicitation of policy overlaps; and on the modelling 
of extended policy portfolios in comprehensive, consistent modelling frameworks.

\section{Keywords}

Carbon valuation. Low-carbon policy portfolios. Low-carbon policy modelling.

\section{Introduction}

The dramatic shifts in lifestyles and development patterns implied by the transition to low-carbon ${ }^{1}$ societies call for an ambitious policy action in both its strength and coverage. Crafting the details of such action requires particular care, considering the stakes: the orders of magnitude of long term studies hint that the cost of deviating from the least-cost option-whatever this optioncould be in the order of some GDP points in 2050 for the most ambitious targets, a level that translates into hundreds of billions of Euros in Europe. From the literature on the topic a set of generic principles emerges that, for some of them, theoretically guarantee cost minimisation and for some others, should at least hedge against massive excess costs.

First and foremost, a requisite to efficient action is some coordination in the policy process. 'Where flexibility' is to be guaranteed to abatement measures: since their climate impact is independent from their geographical origin, emissions should be cut down where it is the cheapest to do so. The rationale is certainly relevant at the European level, and duly taken up by recent governmental reports [78, 16-18, 9]. It also holds at global level, although the semi-failures of the Copenhagen and Doha summits, and the monitoring difficulties inherent to Clean Development Mechanism (CDM) actions, postpone to some unknown future the equalisation of marginal abatement costs across the globe.

\footnotetext{
${ }^{1}$ We will continually refer to 'carbon' when discussing policy options as carbon pricing, a carbon tax, carbon abatement, etc. All greenhouse gases (GHG) are implied on carbonequivalent terms.
} 
The same series of governmental reports, building on a profuse literature, stresses the importance of timing_- when flexibility': despite the persisting economic crisis, delayed action closes, one after another, windows of opportunity to reach the lower concentration levels, while it increases the costs of the still attainable objectives. Policy action is required at least to set Europe on such tracks that its laxer 2050 emission target of an $80 \%$ cut from 1990 levels is still reachable-it is feared that the 2020 objective of a $20 \%$ cut could be too-conservative a milestone on the way to this ambitious 2050 target.

Considering the political process that led to these targets, it is hard to rule out that another emission pathway might induce the same environmental benefits at a lower cost.

Another generic recommendation of policymaking reports is that the distributive consequences of ambitious climate policies should be assessed and controlled, as far as can be: on households, to shield the poorer from strong impacts on their living standards; on firms, to prevent unilateral action to overly degrade their competitiveness on international markets; on governments, ${ }^{2}$ to guarantee that climate policies neither deteriorate (through subsidies and tax cuts) nor improve (through tax and auction proceeds) public budget balances.

At last, many studies underline that the climate policy portfolio will have to be straightforward enough to be accepted by public opinions, considering the constraints envisaged. This, adding to its theoretical properties, points to some form of generalised carbon pricing as the core of policy action-our first section addresses this central instrument, contrasting its treatment by policymaking reports and the scientific literature. However, some more targeted policy measures could be required to circumvent a number of market failures hampering mitigation actions of moderate cost. Our second section details the wide range of such instruments promoted in the policy-oriented literature, but also stresses the weakness of supporting modelling experiments. Our third section concludes on the rich policy modelling agenda emerging from this obvious gap between policy literature and applied studies, even in the restricted framework of cost-efficiency analysis.

\footnotetext{
${ }^{2}$ National accounting distinguishes households, firms and public administrations for the secondary distribution of income. In that sense the public budget impact of policy actions is a matter of income distribution.
} 


\section{Carbon pricing: lessons and limits}

Many if not all low-carbon studies rely partially at least on uniform carbon pricing to trigger the dramatic abatement levels they envision. The economic rationale sustaining such quasi unanimity is well known: by equating marginal abatement costs across agents and localisations, uniform carbon pricing holds the theoretical virtue of minimising the aggregate cost of reaching any abatement target. This rationale governs by and large carbon policymaking, as our first subsection below testifies. We however clarify its practical implications in a second subsection, while we address its limits in a third one.

\section{I.1. A normative value of carbon as a pillar to policy action}

Uniform, economy-wide carbon prices are consistently used in academic and political circles as a support to discussion. On top of their theoretical virtues, they are perceived as concise measures of the 'effort' required to achieve the target envisioned, ${ }^{3}$ and therefore as a basis of comparison between $e$.g. the conclusions of different modelling endeavours, or the stringency of different regional targets. ${ }^{4}$ The static framework of marginal cost equating across agents and regions at some given date, fit for the short-term and modest objectives of the Kyoto protocol, had however to be expanded to dynamic pricing trajectories to match the longer-term, ambitious goals of low-carbon societies.

Following this shift of focus of the climate policy agenda, most energyeconomy models applied to climate policy assessment produced one or several analyses of long-term abatement targets. The $4^{\text {th }}$ assessment report of the Intergovernmental Panel on Climate Change (IPCC) surveys such studies up to

\footnotetext{
${ }^{3}$ Two caveats apply here: first, carbon prices deliver information on the marginal cost, not the total cost, of climate action. Secondly, it is only in the theoretical framework of a benevolent planner maximising utility under perfect foresight, and in a closed economy, that the carbon price strictly matches the marginal social cost of the constraint $[36,48,10]$. The carbon prices computed in other modelling frameworks should not be interpreted beyond the price signals that trigger the desired abatement. The mismatch between the private and social abatement costs has important policy implications that are further addressed below.

${ }^{4}$ By mentioning "targets" (in whichever form these come) we implicitly focus on cost-efficiency analysis, thereby acknowledging its dominance over cost-benefit analysis in both European policy making and European climate policy research. Our third section below further motivates this important angle to our survey.
} 
2007 [53, section 3.3]. Since then, the $22^{\text {nd }}$ round of the Energy Modelling Forum of Stanford University [25 and articles of the same journal issue], the European project ADAM [35 and again articles of the same journal issue], or the RECIPE project [34] added to the available expertise. ${ }^{5}$

The policy implications of these estimates require clarification. While Kyoto marginal costs could be interpreted as prices on a quota market, price trajectories to the middle if not the end of the century do not easily translate into policy action, for contrasted reasons: when estimated globally, because 'first best' agreements at that scale appear too optimistic, at least in the short to mid-term, as testified by the current state of international negotiations; when estimated at the level of the European Union, because of an emerging policy framework incompatible with them-namely, the disconnected provisions of an EU-wide Emissions Trading System (EU-ETS) covering large emitting sites, and of 27 national targets for the remainder of emissions up to $2020 .{ }^{6}$ Uniform pricing trajectories should thus rather be taken as normative assessments of the theoretical least-cost option. Such assessments are nonetheless of high policy significance. Indeed, three reports of the French and British governments $[29,18,28]$ are specifically devoted to establishing normative carbon value trajectories, which they consistently present as pillars to climate policy action. We now turn to an in-depth presentation of these reports, to stress the shortcomings of their use of applied modelling studies.

The reports by the French Conseil d'Analyse Stratégique (CAS) [18] and by the British Department of Energy and Climate Change (DECC) [28] employ similar methods to pinpoint these trajectories: from heteroclite modelling experiments on exogenous emission trajectories they derive carbon values for pivotal years, then interpolate or extrapolate.

\footnotetext{
${ }^{5}$ The ongoing AMPERE and LIMITS European projects should shortly deliver further contributions.

${ }^{6}$ Independent studies confirm the analysis of the European commission itself [15] that the limited amount of emission trading provisioned among the 27 quotas does not allow for marginal cost equating. Our following subsection further addresses this issue.

${ }^{7}$ The report by DECC [28] is explicitly stated as a revision of the one by DEFRA [29], which we therefore do not present at length. DEFRA based its trajectory on the Stern report estimate of the social cost of carbon for 2000, which it updated to $c a € 37$ in 2007 , and then assumed a $2 \%$ annual increase to reach $€ 48$ in 2020 , $€ 58$ in 2030 and $€ 86$ in 2050 (all of these 2008 Euros to allow comparison with Figure 1 below). Our third section below further comments on the corresponding shift from cost-benefit to cost-efficiency analysis.
} 
To be more specific, CAS identifies a pivotal value of $€ 100$ (2008 Euros here and hereafter) in 2030 by averaging the 2030 carbon values computed by three models for a "Europe alone" scenario-2050 European emissions 60\% below their 1990 level without any international offsets. Based on an adaptation of Hotelling's rule the report then advocates extrapolating the 2030 value to 2050 and retropolating it to 2008 using the $4 \%$ discount rate applying to public policy appraisal in France. However, its final recommendation differs: in 2008 it rather connects to a trajectory established back in 2001 [23]; in 2050 it rounds up the $€ 219$ resulting from 20 years of $4 \%$ annual growth to $€ 200$, which it complements with a $€ 150$ to $€ 350$ range-the path between 2030 and this revised value remaining unspecified (Figure 1).

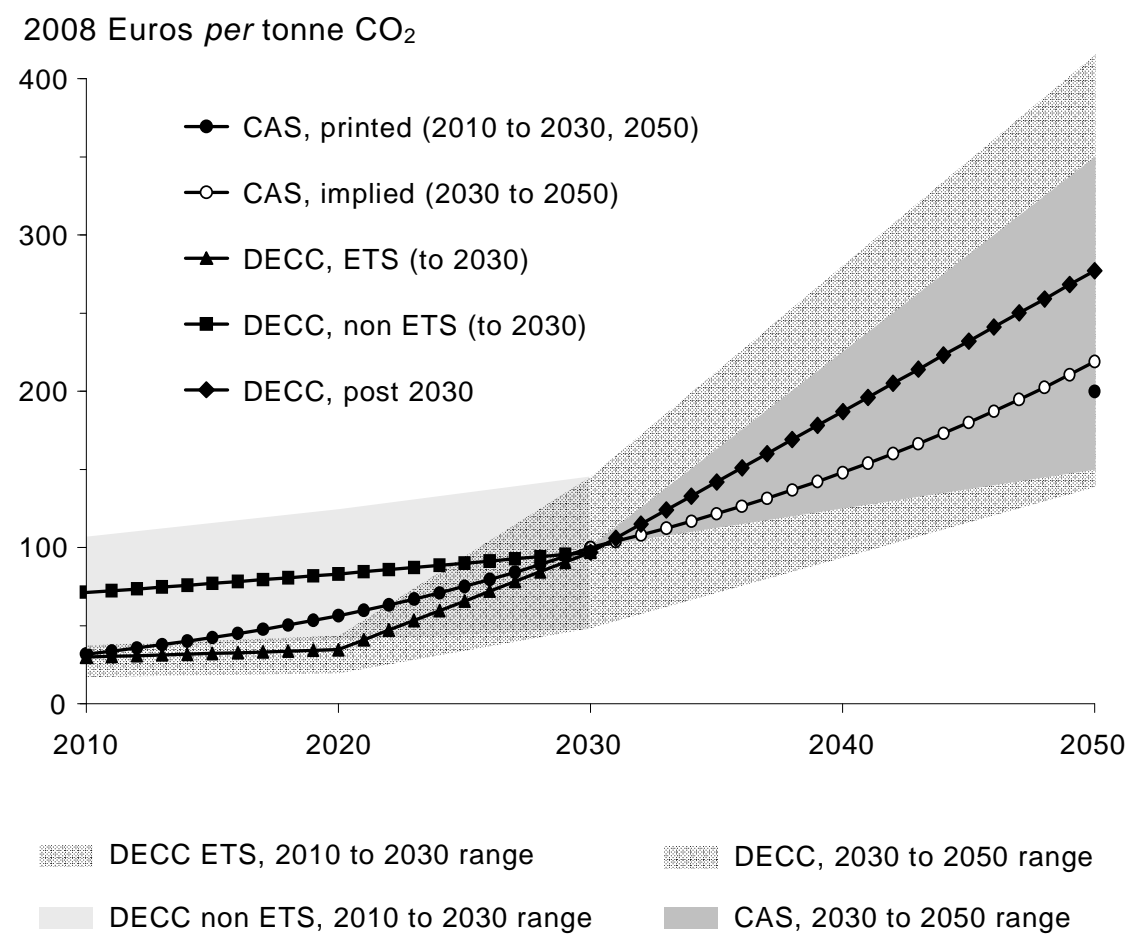

Figure 1 Normative carbon value trajectories from the CAS and DECC reports $^{8}$

${ }^{8} 2009$ British Pounds were converted to 2005 Euros using the 0.778 ratio retained by DECC (31.1/40). 2005 Euros were converted to 2008 Euros using a 0.928 ratio based on inflation data from the Central European Bank. 
Contrary to CAS, DECC acknowledges the European Climate and Energy Package by defining two trajectories up to $2020:{ }^{9}$ one, applying to emissions covered by the EU ETS, derives a 2014 value from modelling experiments, then extends it to 2008 and 2020 using a constant $1.5 \%$ annual rate of increase on a cost-of-carry rationale. The resulting path is complemented by a range defined by the modelling of lower and higher assumptions on fossil fuel prices (Figure 1). Another trajectory applying to non-ETS emissions rests on a 2020 pivotal value, which derives from a set of 2020 bottom-up marginal abatement cost curves (MACCs) drawn from the British Committee on Climate Change (CCC) [20]. This value is retropolated to 2008 considering a $1.5 \%$ rate of annual increase again, then complemented by a $-50 \%$ to $+50 \%$ range inspired by sensitivity analysis on the availability of technical potentials (Figure 1). Beyond 2020, the two trajectories linearly converge to a pivotal 2030 value. This, together with a 2050 value, is drawn from another DECC model's results, adjusted in some unspecified manner to account for other modelling exercises. The latter exercises-including indeed those of the CAS-also sustain a $-50 \%$ to $+50 \%$ uncertainty range on the entire horizon. Both the 2030 and 2050 values are based on the assumption of unrestricted global emissions trading.

For the sake of concision we will not comment on the somewhat misleadingly comparable resulting trajectories-let us simply emphasise that the apparent 2030 consensus partly derives from cross-reference (DECC explicitly quoting CAS), while being backed by strongly contrasted modelling scenarios (full global cooperation vs. "Europe alone" assumption). We rather focus on both reports' ambiguous use of modelling expertise.

On the one hand, modelling results from various models provide the raw material from which the trajectories derive. On the other hand, these results are systematically stripped down to values for some pivotal years, which are systematically rounded up to some central estimate, ${ }^{10}$ while their spreads

\footnotetext{
${ }^{9}$ On the European Energy Package see http://ec.europa.eu/environment/climat/climate_action.htm.

${ }^{10}$ Both reports round up many of the price estimates averaged on different runs. CAS eventually rounds up its own 2050 estimate. DECC argues this avoids giving a misleading sense of precision-a questionable position, as the trajectories will regularly have to be corrected for inflation, and will also be converted to other currencies or deflated, for comparison purposes (see e.g. Figure 1).
} 
provide the loose basis to some accompanying range. ${ }^{11}$ Then, the dynamics of the signal between the pivotal years and beyond are postulated exogenously, on the basis of Hotelling's rule for CAS, and on a simple linear basis for DECC. But the consistency of such assumptions with the trajectories outlined by the initial modelling exercises is not discussed-indeed the latter trajectories are not detailed in either of the two reports. In the case of CAS at least it is obvious that the abstract model that supports adopting Hotelling's rule is incompatible with the dynamics of the POLES, IMACLIM-R or GEMINI-E3 models from which the 2030 pivotal value derives, as it appears from the 4 point estimates reported for these models (Figure 2). The challenge of reconciling such contrasted trajectories should have been highlighted rather than masked.

More fundamentally, both reports lack a minimal discussion of the exogenous emission trajectories imposed to the models to compute carbon value estimates beyond 2020. They do discuss targets in terms of both $\mathrm{CO}_{2}$-equivalent concentrations and cap on temperature increase. However the crucial question of how these targets are translated in emission trajectories accommodating 2020 and 2050 point commitments is unclear. CAS graphically presents its constrained emission trajectories and laconically indicates deriving them from the $4^{\text {th }}$ IPCC report [53]. DECC does not print its own and only reports their source, the SimCap model. Regrettably, the optimality of these trajectories is unaddressed.

\footnotetext{
${ }^{11}$ This with the exception of DECC's price estimate for the ETS sector to 2020, whose lower and higher ranges are set by further modelling through sensitivity analysis.
} 
2008 Euros per tonne $\mathrm{CO}_{2}$

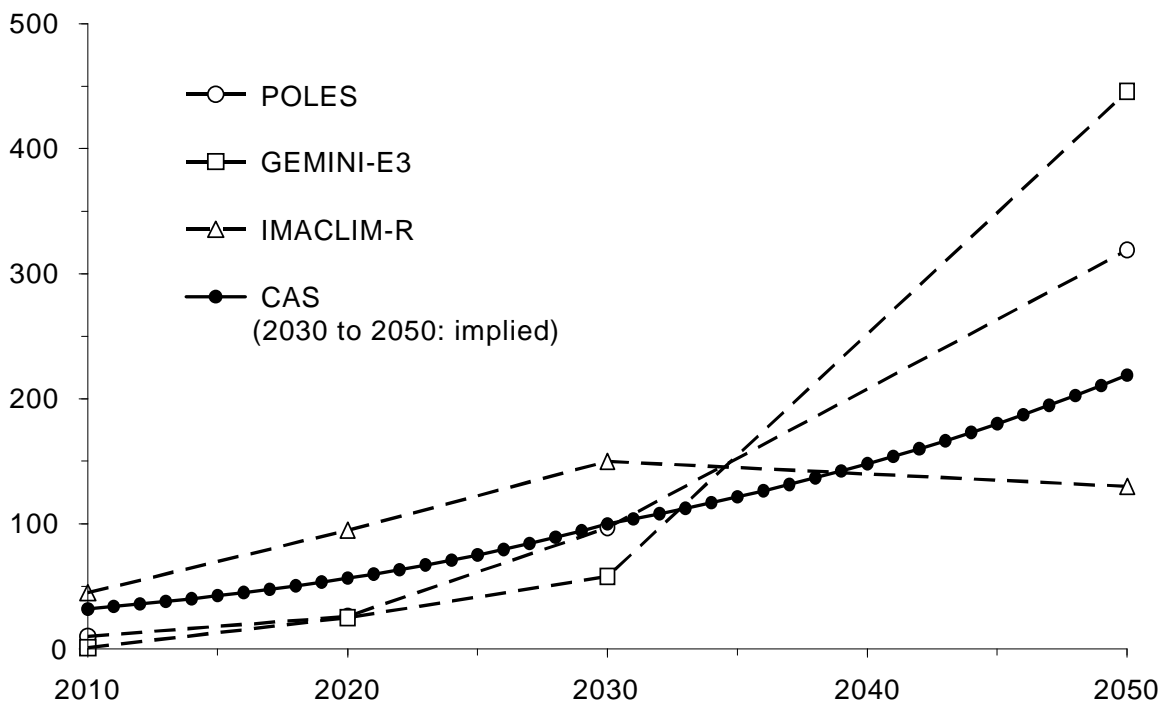

Figure 2 Normative value of carbon from the CAS report and supporting modelling estimates

This is indeed a shortcoming shared by a central piece of low-carbon policymaking in Europe, the European commission's Roadmap for moving to a competitive low-carbon economy in 2050 [21]: this Roadmap claims that the emission trajectory it sketches (emissions $40 \%$ and $60 \%$ below their 1990 level in 2030 and 2040) is a cost-effective pathway to the pre-existing $2050-80 \%$ target; but this is not demonstrated by the accompanying technical document [22], and could indeed hardly be substantiated by any of the 3 models mobilised by the Roadmap, none of them being a macro-economic optimisation model. If anything, the linear quality of the trajectory casts doubts on its optimality. ${ }^{12}$

\footnotetext{
${ }^{12}$ The "cost-efficient" pathways developed by the Conseil d'Analyse Stratégique [19] are similarly questionable; the material complementing the report in its French version clearly establishes they derive from pre-determined carbon price dynamics (see http://www.strategie.gouv.fr/system/files/01_complements_rapp_trajectoire_final.pdf, p. 112, and footnote 30).
} 


\section{I.2. Carbon prices in a 'second best' world}

The policy instruments that jump to mind to embody a normative value of carbon are either a universal carbon tax, or the market price of some comprehensive ETS. The choice between the two options is already partially made in the European Union: the EU-ETS has been extended to 2020 and complemented by national 2020 targets with highly restricted emissions trading. ${ }^{13}$ But this segmented treatment comes at the risk of transgressing the uniform pricing rule. The Commission's expertise itself evaluates that the 2020 ETS market price could be up to $33 \%$ higher than the average 2020 nonETS marginal cost, while not reporting on the country-specific marginal costs that make up this average [15]. Kretschmer et al. [62] estimate a comparable wedge between slightly higher prices, while Bernard and Vielle [8] and especially Böhringer et al. [10] ${ }^{14}$ assess a larger and reversed gap: an average marginal cost of non-ETS abatement up to 7 times higher than the ETS market price in 2020 ([10], "ets+rps" scenario). The two former papers also assess even larger discrepancies in the country-specific non-ETS marginal costs, particularly between western and eastern European countries.

The key question is then that of the excess compliance costs theoretically induced by such forecasted discrepancies. Böhringer et al. [10] compute indeed that the existence of two carbon prices only, one for the ETS and one for the non-ETS emissions (assuming unrestricted trading), increases compliance costs by $c a 50 \%$. The two other papers estimate up to a $40 \%$ supplementary increase from the country specificity of non-ETS commitments. However, Böhringer et al. [10] also develop a set of sensitivity analyses of critical importance: in two out of four cases defined by alternative baseline growth, uniform pricing turns out to induce higher compliance costs than the segmented efforts. The authors identify, as reasons for these heterodox results, that the private and social marginal abatement costs do not match in their modelling framework, on the simple ground that it accounts for the distortions embedded in pre-existing tax systems and international trade. Deviating from uniform pricing can thus be welfare-improving, if the increase in private

\footnotetext{
${ }^{13}$ By the 'EU climate and energy package', see footnote 9.

${ }^{14}$ Böhringer et al. [11] sum up the findings of the three papers. Their research is part of [25].
} 
abatement costs caused by differential pricing is more than offset by terms-oftrade gains, or the alleviation of initial tax distortions.

The consequences for policymaking are to some extent daunting: in a 'second best' world, even one as close to a first best optimum as the computable general equilibrium model of [10], optimal abatement policies cannot be explored by moving the cursor of a uniform carbon price along its monetary axis, at least under the standard assumption of a lump-sum rebate to households. ${ }^{15}$ In fact, Lipsey and Lancaster [66] establish that the smallest departure from 'first best' conditions forbids any preconception on the optimal pricing policy-e.g. that sectors with identical ex-ante tax burdens should have their emissions priced identically.

This does not disqualify the establishment of a normative pricing trajectory: beyond remaining valid as a yardstick to concrete public abatement endeavours, it also constitutes the benchmark value from which deviations have to be considered, to an extent that depends on the magnitude of the preexisting distortions and inertias. The further policy design challenge is to identify these distortions and adapt the pricing policy to them, but also to carefully make the most of the pricing proceeds in second best economic conditions.

Incidentally, this gap between private and social abatement costs echoes the vast literature devoted to the 'double dividend' issue: ${ }^{16}$ the gains from alleviating pre-existing distortions may be such that they supersede the direct technical costs, making up for negative abatement costs. ${ }^{17}$

\section{I.3. Beyond carbon pricing}

The recent literature devoted to low-carbon scenarios describes many instances of failure of pricing policies to induce the most ambitious objectives

\footnotetext{
${ }^{15}$ In less applied settings, another strand of literature demonstrates that the specific inertias of the many abatement options also warrant differentiated prices, particularly under the assumption of imperfect foresight $[63,54,87,88]$.

${ }^{16}$ For a survey see [52], section 8.2.2.1; [53], section 2.4.2.2 sums up the case for a double dividend and provides three further references.

${ }^{17}$ A recent complementary French report [19] innovatively devotes long developments to this issue. By implementing the macroeconometric MESANGE model of the French direction du Tésor it indeed identifies double dividend potentials when carbon tax proceeds are recycled in lower labour taxes.
} 
[85, 79, 25, 35]. Clarke et al. [25] question these inabilities, identifying (beside more straightforward international participation issues, solving limitations and the availability of technological options) ${ }^{18}$ "decline or expansion constraints" in key aspects of the decarbonisation process: in most models the penetration rate of techniques is bounded by asymptotes that are either explicit or induced by constant depreciation rates of the capital stock. ${ }^{19}$

It is hard to draw robust policy conclusions from such evidence: there is no theoretical reason why extreme prices should not end up impacting on penetration rates, e.g. by gradually inducing the early retirement of the existing capital stock-although the practical question of calibrating such fundamental shifts is certainly on the frontier of current climate policy modelling. In that sense the unreachable nature of some targets could be attributed to modelling limitations rather than to a shortcoming of the pricing instrument. This is implicit in the use by some modelling teams of exogenous scenario assumptions on alternate development patterns. ${ }^{20}$ On a similar note the widespread use of carbon pricing in models is to some extent ambiguous: some studies explicitly state that carbon pricing is only meant as a proxy to unspecified policy portfolios better apt to trigger abatement, especially for the most ambitious emission cuts, which require carbon prices reaching heights that raise serious implementation issues.

In a different corpus of literature, stemming from Jaffe and Stavins [56], a number of energy market failures have been identified as warranting policy instruments beyond the market-based ones (see e.g. [7]):

- A series of market imperfections drive a wedge between the socially optimal and the effective innovation effort on low-carbon technologies. Among these, knowledge spillovers prevent innovators from capturing the full return on their investment; insufficient or lacking infrastructure hinders the penetration of some technologies;

\footnotetext{
${ }^{18}$ This latter point is also stressed by Edenhofer et al. [35]: some of the models of the ADAM European project they report on had to be extended with Carbon Capture and Storage (CCS) and combined biomass and CCS options to reach the most ambitious targets envisaged.

${ }^{19}$ Clarke et al. [25] insist on the methodological difficulties of pinpointing the causes of modelling failures. This calls for a thorough examination of some mathematical and parametrical particulars that are out of reach of anyone but the modellers themselves. This is another example that drawing conclusions from any simulation requires a deep understanding of the underlying modelling tool.

${ }^{20}$ See e.g. [27], [40].
} 
fragmented technological markets provide little economic leverage to engage in $R \& D$ programmes characterised by high initial costs, while historical energy market operators have little incentive to innovate. ${ }^{21}$

- Another series of market failures hamper the adoption of low-carbon end-use technologies or behaviours. First, information is fragmented if not sparse on the particulars of the available technology options.

Secondly, capital constraints prevent the more modest households and firms from investing into end-use equipments profitable over the longterm only. A third market failure is caused by misaligned incentives, whereby the beneficiaries of abatement actions are not entitled to them, e.g. the landlord/tenant problem or the split incentives between professional drivers and their companies. At last, intangible costs linked to real or perceived non-monetary characteristics of technology options, limit the adoption of seemingly cost-effective technologies.

It is again possible that the abatement actions impeded by these market failures could be triggered by sufficiently high carbon prices. It is reasonable to think, though, that more targeted, not necessarily market-based policies could tap this abatement potential at a lower social cost; these should thus complement carbon pricing if the cost-efficient option is to be struck. But this conclusion is at the most glimpsed at in peer-reviewed literature, where comprehensive assessments of policy portfolios are sorely missing, ${ }^{22}$ either because the issue is shunned and the uniform pricing rationale still prevails, or because of modelling limitations. 'Grey' literature, on the contrary, offers studies and reports that insist on the necessity to combine a wide range of policy instruments to achieve high rates of decarbonisation, and propose such combinations.

\footnotetext{
${ }^{21}$ Jaffe et al. [55] insist on the concomitancy of the environmental and technological market failures to advocate complementary carbon pricing and R\&D subsidies to climate friendly technologies; this has stimulated some modelling exploration e.g. [12], [41].

${ }^{22}$ Many energy and carbon policy instruments beyond the carbon tax and ETS (green and white certificates, performance standards, border tax adjustments, etc.) have been explored in a body of specific literature, mostly sustained by analytical modelling. What is missing is the comparative assessment of the aggregate social cost of complex policy portfolios (see our third section below).
} 


\section{Targeted policies and measures: a survey}

The set of recent studies and reports matching extended policy portfolios with high rates of decarbonisation in the middle of the century is conveniently split between works commissioned or carried out by public bodies, and works produced by non-governmental organisations (NGOs).

In the first of these categories, France, Germany and the United Kingdom (UK) each produced studies focusing on the way to comply with their national 2050 commitments, a factor 4 emission cut for France, and a factor 5 cut for Germany and the UK. ${ }^{23}$ The French report [16] was commissioned by the French government to an advisory body, the Centre d'Analyse Stratégique (CAS). The German report [9] was commissioned by the German federal environment ministry (BMU) to a consortium of 4 research centres. The British report [20] emanates from the Committee on Climate Change, an independent advisory body. Prior to the CAS 2006 report, France had also issued a shorter note on the Factor 4 objective [78]; besides, in 2008 the CAS reported on French energy perspectives to 2020 and 2050 [17], and the document contains many climate policy recommendations. Some policy measures beyond carbon pricing can also be gleaned from the previously quoted Quinet report on the shadow price of carbon [18], or from a more recent effort focused on identifying abatement pathways to 2050 [19].

In the second category, Greenpeace issued a report in 2005 focusing on EU-25 that envisages a 70\% emission cut in 2050 from 2000 levels [43]. In 2008 the same NGO published a much expanded report at global scale, which describes a 78\% emission cut in 2050 from 1990 levels for OECD Europe [44]. In 2010 the European Climate Fund (ECF) developed another extensive prospective study for the European Union $[32,33]$. The INFORSE network proposes less extended scenarios, which include an EU-27 scenario that envisages a phaseout of fossil energy by 2050 [50]. INFORSE is itself a network of NGOs, among which a militant Zero Carbon Britain, which produced two detailed reports specific to Britain describing a provocative total phase-out of carbon

\footnotetext{
${ }^{23}$ The German and British targets are with reference to 1990 levels, echoing the Kyoto commitments. The French target is more loosely established; CAS [16] assumes it is also with reference to 1990, but it could also be measured against 2003, 2004 or 2005 levels, the years in which the target made its way into the French political agenda.
} 
emissions in the course of 20 years only: [91] updated and expanded to [92].

In 2006 the Negawatt association published a more synthetic report for France [69]. ${ }^{24}$

In echo to our first section, let us note that most if not all the surveyed studies advocate carbon pricing as a core mitigation measure. Carbon prices are however rarely pinned down, and at exogenous levels when so-e.g. by [9] or [44] — with the only exceptions of [20] and [19]. We will come back to this in a further subsection on the modelling support of the studies.

\section{II.1. Advocated policies and measures}

The advocated policies and measures range from the field of energy supply to that of energy demand, as well as to actions beyond the energy markets. ${ }^{25}$

The stress on energy supply is mainly put on accelerating the penetration of renewables. A first policy move should be to restore a 'level playing field' to energy supply competition $[9,43]$ by definitively suppressing any subsidy to conventional electricity production. Some studies also insist on the necessity to even competition between the renewable options themselves: the existing incentives should be thoroughly reviewed, and brought into consistency [9]. Indeed, the reviews by CAS [18] and DECC [28] of the existing instruments in France and the UK reveal large discrepancies in the underlying carbon valuation.

Beyond this prerequisite, most studies recommend complementary measures as feed-in tariffs [43-44, 91-92, 9], legally binding renewable targets [43, 20, 33], together with a simplification of the administrative procedures surrounding electricity production and access to the grid [43, 9, 20,33], whose cost should be borne by a central grid authority rather than billed to the renewable energy projects themselves. Some studies insist on the necessity, for the renewable targets and the feed-in tariffs alike, to preserve a technological diversity crucial to the most ambitious targets [43]. This obviously constitutes a real challenge for tariffs, as it implies a thorough prospective on the future relative costs of the renewable technologies.

\footnotetext{
${ }^{24}$ In a 2011 report, Negawatt updates this scenario but not its policy recommendations.

${ }^{25}$ Section 2.4.2 of [24] provides an extended version of this section.
} 
The targeted increase in renewable energy supply calls for improvements in the electric grid, in the three dimensions of storage, transport and distribution. An upgrade to 'smart grids' should allow balancing power production by decentralised and intermittent units ([17], specifically targeting electric heating; [91], promoting a 'vehicle-to-grid' system—although [92] minimises the contribution of such a system; [33]), if not managing the level and timing of demand against financial incentives ([17]; [43]; [91] and [92], which advocate heterogeneous pricing based on interruptibility of supply).

It is worth mentioning that none of the surveyed studies place a strong emphasis on biofuels. The general stance is one of cautious support, considering both the uncertainties regarding the life-cycle assessment of such energy forms [17], especially when imported from outside the EU [9], and the potential undesired side-effects on food prices [9].

To conclude on energy supply, beyond renewables BMU [9] underlines the necessity to tap the huge potential energy-return gains of combined heat and power (CHP) systems. It supports the German CHP Act, although questioning the level of subsidies to heat providers based on two studies.

Turning to energy demand, mandatory energy efficiency improvements are advocated by ECF [33], and by Greenpeace [43] at the annual level of at least $2.5 \%$ for the private sector and $3 \%$ for the public sector. In the case of France, CAS [17] advocates putting an end to regulated energy prices to attain such ambitious objectives. More specific measures focus on the main potential contributors to energy savings: buildings, transportation, appliances and enduse equipments-while industry is consistently viewed as sensitive enough to market signals to not require complementary measures.

Many studies identify action on buildings as necessary to ambitious targets [91-92, 17, 78, 33], while emphasising their slow dynamics. CAS [17] stresses the highly decentralised nature of decision making in the building sector, and the financial constraints weighing on many of its actors-ZCB [91] insists on the latter as well, and advocates that some of the proceeds of the quota auction it promotes be used to finance investment by the poorer households. ${ }^{26}$ Beyond this, general recommendations include a strengthened and anticipated

\footnotetext{
${ }^{26}$ Although it is specifically pregnant in the building sector where investment costs are high, limited investment capacity also impacts end-use equipments.
} 
development of building regulations for new construction, which should already reach up to 2030 [19]. INFORSE [50] more specifically proposes to raise mandatory building-codes to current low-energy housing levels as early as 2010, and to require that all major renovations include a major energy renovation. It also advocates that passive houses should benefit from a massive R\&D programme to become the basis of updated energy standards. ECF [33] sets a 2020 deadline to this objective. CAS [17] proposes that any new building should be equipped with either heat pumps, renewable heating, or solar thermal hot water. Greenpeace [44] recommends a similar mandatory share of renewable sources to heating and cooling, while CCC [20] calls for some appropriate framework to support the wide-scale deployment of renewable heat. A couple of studies insist on the necessity to monitor these constraints and liabilities [91, 17], based on surveys revealing the 'implementation gap' between regulations and actual performances.

The existing stock should also be subjected to an ambitious refurbishment programme $[9,65,33]$, to hasten convergence between its efficiency and that of new constructions [78, 19]. To implement this convergence ZCB [91] proposes "mandatory energy efficiency improvement at exchange of contract on sale, and when letting". Less targeted measures include tax rebates in exchange for efficiency measures, and a VAT exemption on refurbishment expenses. ZCB also expresses support to the British Warm Front programme (grant programme directed to the poorer households) and the Decent Homes programme (refurbishment of social homes). CAS [17, 19], CCC [20] and ECF [33] support the certificates mandated by the EU directive on the energy performance of buildings, as these concretise the constraint on real estate markets. Among other provisions based on energy performance certificates (EPCs) CAS [17] proposes that

- firms be required to publish an indicator of the energy performance of the buildings they own or occupy,

- landowners be forbidden to increase the rents of the properties that belong to the lower EPC categories,

- an accelerated amortisement of the acquisition or refurbishment costs be allowed to buildings belonging to the higher EPC categories. 
CAS also advocates measures more specific to France. ${ }^{27}$ Alternatively, ZCB $[91,92]$ supports a transition to energy services companies that charge for the provision of energy services (lighting, warmth, hot water, etc.) rather than energy volumes, with the advantage of trusting to such specialised companies the complex optimisation of energy systems. The shift to such market organisation is tentatively started by the Supplier Obligation in the UK, which CCC [20] strongly supports.

Another most targeted energy demand sector is transportation, because of its continued growth and reliance on fossil fuels [17]. General recommendations regard a 'systemic approach' to the transportation problem: the concerted reform of a broad range of public policies related to urban planning, land settlement, supply chains organisation, etc., is necessary to contain the challenging growth of transportation services, and reorient them to carbon sober modes [78, 65, 17-although subordinating such changes to public acceptance, 33, 19]. Radanne [78] particularly urges for early action, considering the dynamics at work. ZCB [91] advocates infrastructure changes as improved cycle lanes (also supported by Greenpeace [43]) and pedestrian facilities. Negawatt [69] or CAS [17] recommend fostering telecommuting and car-sharing, although they do not pinpoint specific instruments. CAS still urges to lift the legal obstacles hampering car-sharing (insurance, expenses eligibility, etc.).

More targeted measures primarily regard passenger cars. Greenpeace [44] advocates strict technical standards and measures to guarantee vehicle size decrease. CAS [19] recommends emission standards anticipated to 2030; CAS [17] pinpoints an objective of $120 \mathrm{~g} / \mathrm{km}$ in 2012 for new personal cars$10 \mathrm{~g} / \mathrm{km}$ stricter than the EU objective, and CCC [20] one of $100 \mathrm{~g} / \mathrm{km}$ in 2020. Both studies agree that standards are necessary on all other classes of motor vehicles as well. CAS [17] also suggests to mandate existing efficiency improving equipments (instant fuel consumption display, tyre pressure gauge, cruise control, etc.). To downsize vehicles Radanne [78] supports a bonus/malus scheme akin to the one introduced in France in $2008,{ }^{28}$

\footnotetext{
${ }^{27}$ Extension to landlords of the tax credits earned by energy saving investments; effective implementation of the obligation of individual accounting for collective heating systems; increase of the VAT rate on cooling systems installation.

${ }^{28}$ The buyer of a new car is subject to a range of taxes or subsidies depending on the car's average $\mathrm{CO}_{2}$ emissions per kilometre.
} 
highlighting it as a good use of the fiscal instrument as a lever on consumer behaviour rather than a source of public money. CCC [20] supports a similar incentive. Radanne also suggests an EU-wide mandatory tie-down of engines, stating this could reduce fuel consumption by $20 \%$-but without addressing the problem of heterogeneity of speed limits in Member States. CAS [17] does by advocating a harmonised upper limit of $130 \mathrm{~km} / \mathrm{h}$, not so much for its direct impact on fuel consumption, as for its indirect impact on the power of cars, allowing for reduced consumption in all driving cycles alike. CAS also stresses the role that training drivers to 'eco-driving' and information campaigns could play; advocates the development of urban tolls and timedependent toll pricing (to reduce fuel waste through congestion); and suggests that a vignette should be reintroduced on a $\mathrm{CO}_{2}$ emission basis considering a $€ 100$ carbon value and an average $14,000 \mathrm{~km}$ per year. CCC [20] also mentions the potential of a $\mathrm{CO}_{2}$-based vignette, without pinpointing levels. Targeted measures on other transportation modes are few. On road freight CAS [17] recommends a kilometre-fee enforced through GPS data. Negawatt [65] advocates a specific taxation of low-cost air transport, without more precision. ZCB [91] goes as far as suggesting that the nationalisation of coach and railways could be required to meet its ambitious objective of a fourfold development of these modes. It also urges to complete the electrification of the British rail network.

Another series of measures concerning energy demand regard appliances and end-use equipments. Recommendations include:

- Extending of environmental labelling to more product information [44, 17, 91, 20]. ZCB [91] specifies that energy ratings should be permanent and clearly visible, to play on reputation effects, and should extend to standby power consumption.

- Strict technical standards [78, 44, 17, 33]. Radanne [78] underlines this should reduce the costs of efficient appliances by guaranteeing them larger markets. CAS [17] specifically mentions the case of light bulbs.

At last, most studies promote complementary measures beyond energy markets. First, the need for a strong, coordinated and immediate R\&D effort is consistently stressed, to foster technical change in energy supply technologies and end-use equipments alike. Some studies identify particular fields of research, which can be split in two: 
- Specific end-uses and end-use equipments: cooling [44]; personal cars [78]; positive energy buildings [17].

- Ancillary technologies: heat storage [44], electricity storage, transport and distribution [91, 17]; carbon sequestration [78, 17, 20]—although some studies exclude it as a non-sustainable option [91, 9].

Although most if not all studies advocate support to renewable technology development, CAS [17] is the only one identifying a priority, namely second generation biomass, stressing that support cannot be generalised considering the current state of public budgets. ${ }^{29}$ On the contrary, ZCB [91] or CAS [19] stress that R\&D programmes should strive to balance their support to competing technologies and let the market elect the most costefficient ones.

A second policy recommendation beyond energy markets regards public awareness campaigns, which many reports advocate, either on loose terms ("energy efficiency"), or on more specific issues. These include driving behaviour, heating and cooling practices, and standby power consumption. In a similar line of thought demonstration projects are advocated on the particular questions of building efficiency by Greenpeace [44], and on the CCS technology by CCC [20].

A third and last field of policy intervention outside energy markets regards the implementation of the ambitious training programmes required to face the escalating demand induced by low-carbon policies on many job markets. Primarily concerned is the construction market broadly understood, from building conception to consultancy on energy performance to refurbishment and construction proper [17, 19, 44, 91]. Again, some stress is put on the timing issue of organising and developing the appropriate training courses [17, 19]. CAS [19] identifies the carbon pricing proceeds as a potential source of funding, while ZCB [92] calls on the proceeds of a border-tax adjustment system-it is indeed the only report opting for such a compensation of competitiveness effects.

\footnotetext{
${ }^{29} \mathrm{CAS}$ also advocates strong public support to $4^{\text {th }}$ generation nuclear and nuclear waste treatment. We have deliberately left out the nuclear phase-out question, which is clear cut in most NGO reports, and strictly echoing national agendas for the British, French and German public reports.
} 


\section{II.2. Modelling support}

The above list of policy options is thus extended in both its coverage and level of detail, especially in some end-use sectors as transportation or buildings. It is however only partially backed by modelling support. To begin with, 8 of the 13 surveyed studies follow a 'storytelling' approach to scenario building [16, $19,{ }^{30} 43,50,69,78$ - as far as can be told from the scant methodological information, 91, 92 $]^{31}$ : they combine detailed exogenous assumptions on the qualitative and quantitative evolution of energy supply and demand, mostly leaning on more or less precisely documented external expertise-which can in turn derive from modelling experiments, or not. Such constructions come at the expense of consistency: there is no guarantee that the underlying expertises share compatible assumptions on such major drivers as economic growth, fossil fuel prices, the costs of technical options or even demography. Beyond this consistency problem, in some policy instances the lack of support is total. Indeed, ZCB [91] develops a minute multigas cap-and-trade system strictly enforcing the 20-year emission phasing-out it promotes, with $40 \%$ of the yearly quota freely allocated to households on a per capita basis, to correct distributional impacts, while the remaining $60 \%$ is auctioned to firms and public institutions, and the auction revenue "ring-fenced for use in easing the transition to a zero-carbon economy". Although on carbon pricing rather than on targeted measures, this offers the most striking example of the imperious necessity of economic assessment: while ZCB cautiously avoids providing estimates, it is quite likely that auction prices for such drastic carbon constraints would reach unsustainable heights, inducing such shifts in the relative prices (including vis-à-vis international prices) as to cause entire sectors of the British economy to collapse-or more likely the policy action to be abandoned under public pressure. ${ }^{32}$

\footnotetext{
${ }^{30}$ CAS [19] uses the POLES model to derive emission pathways that are "cost-effective" in a quite restrictive sense only (minimisation of technical abatement costs of fossil $\mathrm{CO}_{2}$; policy constrained to uniform carbon pricing with constant growth rates). It tests the price trajectories produced by POLES in a set of macroeconomic models to check for sectoral activity and employment impacts, but omits controlling for consistency. Ultimately, neither the advocated sectoral emission pathways nor the recommended policies and measures derive from modelling.

${ }^{31}$ ZCB [91] evokes a transport model p. 137 et seq., but this appears to have both exogenous demand and modal shift, see the table p. 138.

${ }^{32}$ Combet et al. [26] assess substantial GDP and employment losses induced by terms of trade effects for schemes close to ZCB's proposal, in the case of France, and for a $€ 100$ to $€ 400$ per
} 
Four additional studies derive their prospective outlooks of energy systems from models of the 'bottom-up' family [9, 44, 17, 20], thus improving on the consistency of their analyses-only partially so for Greenpeace [44], which articulates the modelling of 4 different institutes without reporting on any harmonisation process. However, bottom-up models picture little economic behaviour if any. Energy demand is explicitly described as a parameter of scenario building: the impacts of the collection of policy measures envisioned are-mostly undocumented - exogenous estimates. In short, the advocated policy portfolios generally lack support from (i) microeconomic expertise, which could assert that the wide array of advocated measures match the often dramatic impacts attributed to them, and (ii) a macroeconomic integrating framework, in which these measures could interact to form a consistent economic and energy system picture, accounting for the feedbacks from equipment goods, capital or labour markets. The latter shortcoming indeed constricts aggregate impact assessment to technical costs and forbids reporting on GDP or welfare costs. ${ }^{33}$

Lastly, the ECF study [32,33] distinguishes itself by founding its scenarios on a combination of bottom-up and top-down modelling approaches. Although the report lacks a thorough methodological exposition, it appears from its appendixes that bottom-up expertise (if not modelling: a "Mc Kinsey [power] generation model" is mentioned, but not referenced), extending to energy demands and energy efficiencies, together with the investment costs of electric vehicles, heat pumps and biofuels penetration, are fed into a computable general equilibrium model to assess the macro-economic impacts of lowcarbon scenarios. The extension of the modelling scope to macro-economic variables is an obvious improvement over the other approaches. However, energy demands, at the heart of the modelling architecture, remain exogenous. The links between the advocated policies and measures and the targeted energy and carbon efficiency improvements are again a series of hardly connected educated guesses.

tonne $\mathrm{CO}_{2}$ carbon tax. It is doubtless that the prices induced by ZCB's proposal would rapidly exceed $€ 400$ per tonne $\mathrm{CO}_{2}$.

${ }^{33}$ It must be noted that this scope limitation is voluntary for CCC [20], considering the uncertainty surrounding impacts beyond the energy markets. Hourcade and Ghersi [48] propose a disambiguation of climate policy 'costs'. 


\section{A blueprint for further policy modelling research}

Addressed from the viewpoint of the modeller, the above panorama calls for extensive further policy analysis. Both our sections on carbon pricing and targeted measures lay some lineaments that we can now develop and weave into a research agenda. We purposely limit it to cost-efficiency analysis, thereby both acknowledging current EU policymaking and shunning from the current debate surrounding cost-benefit analysis (Box 1). In this latter choice we follow Dietz [30] or Yohe and Hope [90], who react to the persisting if not increasing failure of damage assessment to reach any form of consensus. ${ }^{34,35}$ As Kopp and Mignone [60] establish (without formally endorsing it), this shift is a transcription to climate affairs of Baumol's prescription to degrade the Pigouvian policy principles when faced with too-elusive externality costs [6].

We also avoid opening our renewed agenda to the transversal issue of uncertainty: the development of stochastic programming and the increasing use of Monte-Carlo simulations appear appropriate improvements on the way to facing this important challenge, although they should be more systematically applied beyond climate sensitivity and damage uncertainties. ${ }^{36}$

\footnotetext{
${ }^{34}$ Dietz observes that the gap of about one order-of-magnitude between the plausible ranges of the social cost of carbon and the corresponding marginal abatement costs that he estimated in 2010 [31] has likely been amplified by more recent publications.

${ }^{35}$ Ackerman and Stanton [2] also advocate focus on cost-efficiency analysis, not only because the social cost of carbon is highly uncertain, but also because they reassess the corresponding uncertainty range to values confidently greater or equal to the estimated range of the marginal costs of the total global abatement potential up to 2050.

${ }^{36}$ Many of the references of Box 1, beginning with [51], address uncertainty through Monte Carlo techniques. Haurie et al. [47] and articles of the same journal issue report on recent applied research on the uncertainty about socio-economic factors including behavioural parameters, the availability of technological options, the outcome of international negotiations, etc. The series of papers in Filar and Haurie [37], particularly the first chapter by the two editors, conceptualises the issue and introduces the methods.
} 
The 2007 Stern review [82] and the 2010 United States Interagency Group on the Social Cost of Carbon [51] successively fuelled an escalating controversy on cost-benefit analysis, ${ }^{37}$ including three recent special journal issues [61, 67 and parts of 45]. The most debated points are: ${ }^{38}$

- Climate sensitivity, i.e. the long-term impact of $\mathrm{CO}_{2}$ concentration on temperatures, and particularly the consequence of considering a 'fat' rather than a 'thin' tail to its probability distribution [89, 76, 77, 83, 72].

- The damage function linking temperature change to economic impacts. The quadratic form introduced by Nordhaus [70] is suspected not convex enough, and alternatives explored $[89,76,83,3,30,59] \cdot{ }^{39}$ Besides, the available damage estimates are criticised as incompletely covering the many impact channels [30, 60, 67, 83]. Kopp and Mignone [60] also stress how inappropriate a social cost of carbon is if measured off a baseline already beyond some 'tipping point' of the climate system (i.e. when the damage function is only piecewise convex).

- The discount rate, which in the standard Ramsey framework dissociates in the rate of pure time preference and the constant relative risk aversion. Prescriptive $v s$. descriptive approaches to discounting lead to markedly higher $v s$. lower assessments of the social cost of carbon i.e. the optimal mitigation requirements $[71,60,4,83]$

Uncertainty on these three dimensions dramatically increases the range of plausible social costs of carbon. Fearing that this uncertainty is in part irreducible, some recent papers more or less openly question the ultimate contribution of cost-benefit analysis [30, 89, 90, 83].

Box 1

Current controversies on cost-benefit analysis

On this contained agenda, the first field of policy research emerging from our survey regards the establishment of cost-efficient carbon pricing trajectories to

\footnotetext{
${ }^{37}$ Some earlier caveats on a sound use of integrated assessment modelling are provided by Schneider [81], who stresses the contribution of Ravetz [80].

${ }^{38}$ Another increasingly researched question is the consequences of damages impacting the capital stock [59] [83], the growth rate [75], utility [59], technical progress [68] [83] or its rate of change [68] [83], rather than (standardly) economic output.

${ }^{39}$ Similarly, [1] questions the optimism of several elements of the disaggregated treatment of damages by the FUND model.
} 
point-in-time mitigation commitments. ${ }^{40}$ When assessing such commitments, most available studies indeed constraint their pricing trajectories to either some transposition of Hotelling's rule, or ex-ante full-blown emission trajectories encompassing the targets-see our section I.1 on prominent policy reports and Box 2 for a generic formulation of modelling approaches. The rationale for Hotelling is explained at length in $[18] .{ }^{41}$ However this same report makes it very clear that Hotelling applies only if the policy objective is specified as a $\mathrm{CO}_{2}$ concentration ceiling, and as long as this ceiling is not reached. Although it is not their primary purpose, Vogt-Schilb and Hallegatte [87] demonstrate that the optimal time profile of emissions varies substantially if policy objectives are rather expressed in terms of constraints at pivotal years. ${ }^{42}$ They derive this insight from a model in which they depict the inertia of abatement potentials: the multiple specific stock dynamics of end-use equipments, energy production, the building stock and ultimately urban and transportation infrastructures, shape the dynamics of abatement options. Three other determinants of the development of the mitigation potential are:

- Demographics, which impact on the available manpower, on public budgets in many European countries where pension systems are public, and also on the average savings rate: they strongly influence growth and emissions, but also the resource available to finance abatement actions.

- Fossil fuel prices, the sum of extraction costs and rents. Their specific dynamics, conventional and unconventional resources alike, constitute another price signal that will all the more impact mitigation measures as stocks deplete-conversely, ambitious mitigation cannot but reduce the pressure on fossil fuel markets, thereby inducing a 'rebound' of consumption.

\footnotetext{
${ }^{40}$ The policy conclusions of the ADAM project [58] touch on this unresolved challenge of dynamic efficiency.

${ }^{41}$ Theoretically amended to account for the rate of carbon uptake by natural reservoirs.

${ }^{42}$ They also compute a $62 \%$ excess cost from the loss of 'when flexibility' implied by forcing point-in-time targets rather than some aggregate carbon budget at a 2050 horizon-constraint (7b) rather than (7a) in our Box 2.
} 
A generic, discrete carbon/economy model can be defined as: ${ }^{43}$

$$
\begin{gathered}
U_{t}=u_{t}\left(\left(1-s_{t}\right) Y_{t}, \alpha D_{t}\right) \\
Y_{t}=f_{t}\left(K_{t}, \beta D_{t}, \tau_{t}\right) \\
K_{t+1}=k_{t}\left(K_{t}, s_{t} Y_{t}\right) \\
e_{t}=\varepsilon_{t}\left(\tau_{0}, \ldots, \tau_{t}\right) \\
D_{t}=d\left(\sum_{i=0}^{t} e_{i} Y_{i}\right)
\end{gathered}
$$

where at each time period $t$ (we drop $t$ subscripts for readability):

- Social welfare $U$ is a function $u$ of output $Y$ minus savings $s Y(\partial u / \partial Y>0$, $\partial u / \partial s<0)$ and of an $\alpha$ share of impacts $D \geq 0$, which turn to harmful damages beyond some threshold $\bar{D}(0 \leq \alpha \leq 1, \forall D>\bar{D} \partial u / \partial D<0){ }^{44}$

- Output net of damages $Y$ is a function $f$ of the capital stock $K(\partial f / \partial K \geq 0)$, of a $\beta$ share of $D(\beta \geq 0, \beta+\alpha \leq 1, \forall D>\bar{D} \partial f / \partial D<0)$ and of a marginal technical abatement $\operatorname{cost} \tau \geq 0$, which turns harmful beyond some threshold $\bar{\tau}(\forall \tau>\bar{\tau} \partial f / \partial \tau<0){ }^{45}$

- Capital stock $K$ accumulates through time according to a function $k$ considering savings $s Y(\partial k / \partial K>0, \partial k / \partial s Y>0) .^{46}$

- Emission intensity of output $e$ is a decreasing function $\varepsilon$ of the trajectory of $\tau(\partial \varepsilon / \partial \tau<0)$.

- Impacts $D$ are an increasing function of cumulative emissions $\Sigma e Y$ $(\partial d / \partial \Sigma e Y>0)$-eq. (5) aggregates climate sensitivity and the damage function of Box 1 .

\footnotetext{
${ }^{43}$ For the sake of generality we abstract from identifying even the most common parameters $(e . g$. demography).

${ }^{44} u$ is time-dependent for the sake of generality, although most models with explicit utility functions assume them constant through time. The conditions on $\alpha$ and $\beta$ allow covering different entry points of damages (see footnote 38) as well as not accounting for impacts $(\alpha=\beta$ $=0$ ). Considering $\bar{D}$ allows extending to models that compute a net positive impact of low temperature increases.

${ }^{45} f$ is time-dependent to account for exogenous productivity growth, a trait common to many models. To cover endogenous growth the growth trajectory of $K$ or $Y$ to $t$ could be added as argument to $f$. The weak condition on $\partial f / \partial K$ aims at covering models with exogenous $Y$. Considering $\bar{\tau}$ allows covering models that compute a net positive impact of low carbon pricing.

${ }^{46} k$ is time-dependent to cover the complex, disaggregated capital dynamics of some models.
} 
In this framework, provided damages are accounted for $(\alpha+\beta=1)$ and considering a pure rate of time preference $\rho$, standard cost-benefit analysis is

$$
\operatorname{Max}_{s, \tau} \sum_{t=0}^{+\infty} e^{-\rho t} U_{t}
$$

Alternatively, cost-efficiency analysis abstracts from impacts $(\alpha=\beta=0)$ to consider the same objective function (6), subject to either some carbon budget up to $T^{47}$

$$
\sum_{t=0}^{T} e_{t} Y_{t}=A
$$

or more pragmatically some emission target at date $T$ :

$$
e_{T} Y_{T}=A_{T}
$$

However, many published low-carbon modelling studies enforce a stronger

$$
\left\{e_{1} Y_{1}, \ldots, e_{T-1} Y_{T-1}\right\}=\left\{A_{1}, \ldots, A_{T-1}\right\}
$$

[e.g. 57, 10,62], while another set of studies alternatively add

$$
\forall t>0 \quad \tau_{t}=(1+r)^{t} \tau_{0},
$$

with some exogenous $r$ related to the discount or interest rate $[85,46,13,14]$ (see also footnote 12) or the consumer price index [5]. In some studies relying on it condition (8) is the pathway of a separate analysis [57], while in some others it is explicitly a simple interpolation [10,62]. Similarly, condition (9) aims at optimality by applying Hotelling's rule (see section I.1) ${ }^{48}$ No study however offers proof that (8) or (9) do not constrain $\tau$ (and $s$ if warranted) to a suboptimal pathway in their own modelling framework. ${ }^{49}$

Box 2 A generic formulation of low-carbon modelling

\footnotetext{
${ }^{47}$ In our simplified framework this is the closest to a concentration ceiling, a cap on temperature change or a radiative forcing constraint.

${ }^{48}$ Excluding [5], which must be credited for explicitly acknowledging non-optimality.

${ }^{49}$ Note that this analysis covers recursive models, although by definition these drop (6) (exogenising $s$ if they are macroeconomic models); they address (7) through either (8) [10, 62] or a trial-and-error implementation of (9) [5].
} 
- Technical progress, which defines how input substitution flexibilities evolve with each capital vintage. It is driven by both research and development activities, and learning-by-doing. The former activity and the latter phenomenon must be accounted for to determine, even if only tentatively, the 'carbon intensity' embodied in successive capital vintages.

The four interacting dynamics should be integrated in some intertemporal optimisation framework, that in the European case could target a 2050 emission objective, with at least carbon pricing and public R\&D trajectories as variables. The task is not out of reach of some models currently in use, and indeed some of the dynamic interactions at play have already been touched upon—particularly as regards trajectories of R\&D investment, see e.g. [12], [41]. Of course the resulting pricing pathways, as any modelling outcome, would be dependent on a particular set of assumptions (including those determining the discount rate, which attracted great attention in the wake of the Stern review), but at least these could be explicitly discussed, and the policymaker allowed more informed decisions.

The second field of investigation emerging from our survey is the Terra Incognita beyond first best static policy design. Section I.2 echoes the firmly established fact that the uniform pricing rationale is a challenge to enforce in real world 'second best' economies, where market distortions can be large enough to significantly increase costs if these are distributed in a standard way (taxes or auction proceeds rebated lump-sum to households, grandfathered permits). Böhringer et al. [10] identify two such distortions:

- Pre-existing taxes and subsidies. These impact public budgets, and the shift in their fiscal bases or beneficiary activities induced by carbon pricing must be accounted for: some carefully differentiated pricing could lower the social cost of the carbon constraint by minimising its impact on the pre-existing public financing structure. ${ }^{50}$

\footnotetext{
${ }^{50}$ This is further complicated by the varying possible assumptions about public budget constraints. A standard assumption is that of the 'budget neutrality' of the reform, mostly defined as a maintained budget balance under the constraint of constant real public expenditures. This implies selecting some adjustable tax rate that allows balancing the induced variations. It is obvious that the cost of any abatement target will depend on the selected adjustable rate and the induced shift in any pre-existing distortions.
} 
- Terms-of-trade effects. The degree of exposure to international competition is highly variable across sectors, from poorly differentiated raw materials to local services. It is hard to rule out that some moderate increase of the carbon price laid on unexposed activities to compensate for carbon price cuts granted to exposed sectors could lower the social cost of some mitigation objective.

These two types of distortion are easily modelled as they rest upon the interplay of readily observable relative prices. More controversial distortions regard some 'imperfect' features of e.g. labour markets in many European countries, where numerous regulations and transaction costs prevent full clearing through prices.

The consequences of such second best features on policymaking do not receive the attention they deserve, considering the stakes of significantly reduced if not inverted abatement costs illustrated by the formerly quoted IPCC survey [51]. They should be explored in a pragmatic way, notwithstanding the unsettled academic dispute whether the benefits from alleviating distortions should be attributed to the climate policy per se or not-a point arguably irrelevant to the policymaker. Case studies firmly anchored in some dominating traits of the real world economies can contribute to elicit them. To be thorough these should give greater attention to the rebating option that closes the loop of any price-based policy, as CAS [19] indeed does. In that regard attempts at pinpointing 'the' optimal recycling scheme through modelling are probably vain, as they are likely to point at some corner solution blatantly ignoring the political constraints that weigh on public decision making. Still, it should be made clearer to the policymaker how contrasted recycling options lead to contrasted welfare and distributional impacts.

A third field of further research regards the microeconomic elicitation of incentive overlaps. Section II demonstrates that the available literature on lowcarbon policy portfolios is more a catalogue of policy measures than anything else, with too little attempts at rationalising the corresponding wide array of incentives. These incentives thus partly overlap, see e.g. the manifold measures simultaneously targeting the speed, power, carbon efficiency, equipment, road access, etc., of personal cars. On a strict efficiency ground this comes at the risk of exaggerating the incentives to some forms of abatement, thereby incurring unnecessary costs - it is a fact established since Tinbergen [84] that public policy instruments should be sufficiently focused to 
address one market failure and one only, ${ }^{51}$ although this conclusion has been qualified in different ways by recent research, e.g. by Bennear and Stavins in a general second best setting [7], or by Lecuyer and Quirion as hedging against the risk of pricing policy failure [65]. It is also a threat to policy implementation, as it manifestly contradicts the 'pedagogy' principle that an ambitious carbon policy should be stripped down to the most simple possible expression if it is to gather public acceptance.

A body of literature exists that compares the merits of different policies aimed at the same carbon abatement options, mostly in an analytical microeconomic framework-Fischer and Preonas [39] provide a survey extending beyond their focus on renewable energy promotion. It should be systematically extended to more of the policy options identified in the grey literature on low-carbon societies, under the Tinbergen requirement that each of these options could be pointed at a particular market failure, which should be analytically qualified as well. The tentative framework developed by Oikonomou and Jepma [74] for analysing the interactions of policy instruments could provide the basis for a more systematic approach. It should also be complemented, as its authors indeed call for, by numerical analyses simulating the particular conditions of the current economies, and indeed exploring some of the anticipated trends of the relevant set of parameters, along the lines of Goulder et al. [42] or Fisher and Newell [38]—Lecuyer and Bibas [64] offer more references of that effect.

Last but not least, the three outlined research strands should eventually be brought together into an integrated framework of analysis that could be applied to policy assessment: it is necessary that the carbon pricing trajectories resulting from the first and second lines of research, and the policies and measures emerging from the third one, should be assessed simultaneously, lest some significant interactions and feedbacks be disregarded, at the cost of economic efficiency.

This last task is probably the most daunting: even if their numbers are cut down by the elicitation of a rational combination of incentives, most of the recommendable policies and measures play at a scale, and are justified by market imperfections, which comprehensive modelling structures will be hard put to model. The hybridising methods explored to bridge the gap between

\footnotetext{
${ }^{51}$ This point has been repeatedly made by the OECD in recent years [73].
} 
bottom-up and top-down energy modelling (see [49] and articles of the same journal issue) offer the beginning of an answer to these challenges, but the beginning only. Their further development is essential, if the current fragmented economic expertise is to be built up into a comprehensive vision of future low-carbon policy portfolios.

\section{Conclusion}

In this paper we have surveyed central pieces of the scientific and policyoriented literature on low-carbon futures. We first stressed the somewhat confusing use of modelling expertise by French and British governmental endeavours to pinpoint a normative value of carbon, the admitted backbone of climate policies. We then highlighted the striking gap between the wide array of policy instruments envisioned in the policymaking literature and the scarce modelling expertise on policies and measures beyond carbon pricing. These shortcomings inspire us an updated, pragmatic low-carbon policy modelling agenda insisting on (i) the assessment of cost-efficient trajectories to point-intime targets freed from any preconceived emission or pricing pathway; (ii) the exploration of the terra incognita beyond uniform pricing, accounting for preexisting distortions or inertias of abatement options; (iii) a systematic elicitation of incentive overlaps and possible justifications of them; (iv) an integration of these key features in some consistent modelling framework.

A transversal conclusion to our research is that low-carbon modelling studies appear too isolated from, on one side, a scientific literature that has long started to come to grasp with some of the real-life complexities disqualifying the disincarnate 'first best' policy options; on the other side, a policymaking corpus whose diversity echoes the same real-life complexities, in a probably more comprehensive but doubtlessly less articulate manner. Beyond the scientific challenges we outline, it is only by opening to both influences, leaning on the former one to rationalise the latter, that applied modelling studies can significantly enhance their policy relevance, thereby hopefully increasing their necessary influence on the policymaking process. 


\section{Acknowledgement}

An earlier version of this paper was written during a visiting year at and with the gratefully acknowledged support of the Fondazione Eni Enrico Mattei, Isola di San Giorgio Maggiore, 30124 Venice, Italy. Comments by JeanCharles Hourcade, Franck Lecocq, the editor-in-chief of the journal and 3 anonymous reviewers helped improve the paper. The contents remain the author's sole responsibility.

\section{References}

1. Ackerman, F., Munitz, C. (2012). Climate damages in the FUND model: A disaggregated analysis. Ecological Economics, 77, 219-224.

2. Ackerman, F., Stanton, E. A. (2012). Climate risks and carbon prices: Revising the social cost of carbon. Economics: The Open-Access, OpenAssessment E-Journal, 6, 25 p.

3. Ackerman, F., Stanton, E. A., Bueno, R. (2010). Fat tails, exponents, and extreme uncertainty: Simulating catastrophe in DICE. Ecological Economics, 69(8), 1657-1665.

4. Anthoff, A. L., Tol, R. S. J. (2013). The uncertainty about the social cost of carbon: A decomposition analysis using FUND. Climatic Change, 117(3), 515-530.

5. Barker, T., Scrieciu, S. (2010). Modeling low climate stabilization with E3MG: Towards a 'new economics' approach to simulating energyenvironment-economy system dynamics. The Energy Journal, Special Issue: Endogenous technological change and the economics of atmospheric stabilization, 137-164.

6. Baumol, W. (1972). On taxation and the control of externalities. American Economic Review, 62(3), 307-322.

7. Bennear, L. S., Stavins, R. N. (2007). Second-best theory and the use of multiple policy instruments. Environmental and Resource Economics, 37(1), 111-129.

8. Bernard, A., Vielle, M. (2009). Assessment of European Union transition scenarios with a special focus on the issue of carbon leakage. Energy Economics, 31(S2), S274-S284 
9. BMU (2008). Lead Study 2008: Further development of the 'Strategy to increase the use of renewable energies' within the context of the current climate protection goals of Germany and Europe. German federal ministry for the environment, Nature conservation and nuclear safety (BMU), Division KI III 1, 188 p.

http://www.bmu.de/fileadmin/bmuimport/files/english/pdf/application/pdf/leitstudie2008_en.pdf. Accessed November 2013.

10. Böhringer, C., Löschel, A., Moslener, U., Rutherford, T. F. (2009). EU climate policy up to 2020: An economic impact assessment. Energy Economics, 31(S2), S295-S305.

11. Böhringer, C., Rutherford, T. F., Tol, R. S. J. (2009). The EU 20/20/2020 targets: An overview of the EMF22 assessment. Energy Economics, 31(S2), S268-S273.

12. Bosetti, V., Carraro, C., Duval, R., Sgobbi, A., Tavoni, M. (2009). The role of $\mathrm{R} \& \mathrm{D}$ and technology diffusion in climate change mitigation: New perspectives using the WITCH model. OECD Economics Department Working Paper, 664, 53 p. http://search.oecd.org/officialdocuments/displaydocumentpdf/?doclangu

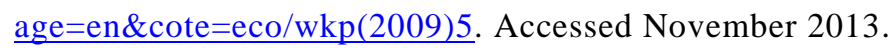

13. Calvin, K., Edmonds, J., Bond-Lamberty, B., Clarke, L., Kim, S. H., Kyle, P., Smith, S. J., Thomson, A., Wise, M. (2009). 2.6: Limiting climate change to $450 \mathrm{ppm} \mathrm{CO}_{2}$ equivalent in the 21 st century. Energy Economics, 31(S2), S107-S120.

14. Calvin, K., Patel, P., Fawcett, A., Clarke, L., Fisher-Vanden, K., Edmonds, J., Kim, S. H., Sands, R., Wise, M. (2009). The distribution and magnitude of emissions mitigation costs in climate stabilization under less than perfect international cooperation: SGM results. Energy Economics, 31(S2), S187-S197.

15. Capros, P., Mantzos, L., Papandreou, V., Tasios, N. (2008). Modelbased analysis of the 2008 EU policy package on climate change and renewables. Report to the European Commission - DG ENV, 49 p. http://ec.europa.eu/clima/policies/package/docs/analysis_en.pdf. Accessed November 2013. Appendixes (914 p.): http://ec.europa.eu/clima/policies/package/docs/analysis_appendix_en.p df. Accessed November 2013. 
16. CAS (2006). Division par quatre des émissions de gaz à effet de serre de la France à l'horizon 2050. Report of the Conseil d'Analyse Stratégique, Paris, France: La Documentation Française, 142 p. http://www.ladocumentationfrancaise.fr/var/storage/rapportspublics/064000757/0000.pdf. Accessed November 2013.

17. CAS (2008a). Perspectives énergétiques de la France à l'horizon 20202050. Report 12 of the Conseil d'Analyse Stratégique, Paris, France: La Documentation Française, 325 p.

http://lesrapports.ladocumentationfrancaise.fr/BRP/074000659/0000.pdf . Accessed November 2013.

18. CAS (2008b). La valeur tutélaire du carbone. Report 16 of the Conseil d'Analyse Stratégique, Paris, France: La Documentation Française, 423

p.

http://lesrapports.ladocumentationfrancaise.fr/BRP/094000195/0000.pdf . Accessed November 2013.

19. CAS (2012). Trajectoires 2020-2050 vers une économie sobre en carbone. Report 46 of the Conseil d'Analyse Stratégique, Paris, France: La Documentation Française, 227 p. http://www.strategie.gouv.fr/system/files/2011-12-12-trajectoires_20202050_-_developpementdurable.pdf.pdf. Accessed November 2013.

Complements (141 p.):

http://www.strategie.gouv.fr/system/files/01_complements_rapp_traject oire final.pdf. Accessed November 2013. Partial English translation (119 p.):

http://www.strategie.gouv.fr/system/files/cas_pathways_2020_2050_jul y2012_0.pdf. Accessed November 2013..

20. CCC (2008). Building a low-carbon economy - the UK's contribution to tackling climate change. Edinburgh, UK: The Stationery Office. http://archive.theccc.org.uk/aws3/TSO-ClimateChange.pdf. Accessed November 2013.

21. CEC (2011a). A Roadmap for moving to a competitive low carbon economy in 2050. COM(2011) 112 final, 8 November 2011 http://eurlex.europa.eu/LexUriServ/LexUriServ.do?uri=COM:2011:0112:FIN:EN :PDF. Accessed November 2013.

22. CEC (2011b). Impact assessment. Accompanying document to the Roadmap for moving to a competitive low carbon economy in 2050. 
SEC (2011) 288 final, 8 March 2011

http://eur-

lex.europa.eu/LexUriServ/LexUriServ.do?uri=SEC:2011:0288:FIN:EN: PDF. Accessed November 2013.

23. CGP (2001). Transports : choix des investissements et coûts des nuisances. Report to the Commissariat Général du Plan, Paris, France: La Documentation Française, 325 p.

http://lesrapports.ladocumentationfrancaise.fr/BRP/014000434/0000.pdf . Accessed November 2013.

24. Château, B., Rossetti di Valdalbero, D. (Eds.) (2011). World and European energy and environment transition outlook. European commission directorate-general for research and innovation report, 154 p. http://ec.europa.eu/research/social-sciences/pdf/publication-wetot_en.pdf. Accessed November 2013.

25. Clarke, L., Edmonds, J., Krey, V., Richels, R., Rose, S., Tavoni, M. (2009). International climate policy architectures: Overview of the EMF 22 international scenarios. Energy Economics, 31(S2), S64-S81.

26. Combet, E., Ghersi, F., Hourcade, J.-C., Thubin, C. (2009). Économie d'une fiscalité carbone en France. Report to the Confédération Française Des Travailleurs, 139 p.

27. Crassous, R., Hourcade, J.-C., Sassi, O. (2006). Endogenous structural change and climate targets: modeling experiments with IMACLIM-R.

The Energy Journal, 27, Special Issue 1: Innovation Modeling Comparison Project.

28. DECC (2009). Carbon valuation in UK policy appraisal: A revised approach. Climate Change Economics, Department of Energy and Climate Change, $128 \mathrm{p}$.

https://www.gov.uk/government/uploads/system/uploads/attachment_da ta/file/245334/1_20090715105804_e carbonvaluationinukpolicyapp raisal.pdf. Accessed November 2013.

29. DEFRA (2007). The social cost of carbon and the shadow price of carbon: What they are and how to use them in economic appraisal in the UK. DEFRA Economics Group, $21 \mathrm{p}$. http://archive.defra.gov.uk/evidence/series/documents/shadowpriceofcar bondec-0712.pdf. Accessed November 2013. 
30. Dietz, S. (2012). The treatment of risk and uncertainty in the US social cost of carbon for regulatory impact analysis. Economics: The OpenAccess, Open-Assessment E-Journal, 6, 12 p.

31. Dietz, S., Fankhauser, S. (2010). Environmental prices, uncertainty, and learning. Oxford Review of Economic Policy, 26(2): 270-284.

32. ECF (2010a). Roadmap 2050. A practical guide to a prosperous, lowcarbon Europe. Technical analysis. 99 p.

http://www.roadmap2050.eu/attachments/files/Volume1_fullreport_Pres sPack.pdf. Accessed November 2013.

33. ECF (2010b). Roadmap 2050. A practical guide to a prosperous, lowcarbon Europe. Policy recommendations. 35 p.

http://roadmap2050.eu/attachments/files/Volume2_Policy.pdf. Accessed November 2013.

34. Edenhofer, O., Carraro, C., Hourcade, J.-C., Neuhoff, K., Luderer, G., Flachsland, C., Jakob, M., Popp, A., Steckel, J., Strohschein, J., Bauer, N., Brunner, S., Leimbach, M., Lotze-Campen, H., Bosetti, V., de Cian, E., Tavoni, M., Sassi, O., Waisman, H., Crassous-Doerfler, R., Monjon, S., Dröge, S., van Essen, H., del Río, P., Türk, A. (2009). RECIPE - The economics of decarbonization. Synthesis report, $96 \mathrm{p}$. http://www.pik-potsdam.de/research/research-domains/sustainablesolutions/research-act-intl-climate-pol/recipe-groupspace/workingpapers/recipe-synthesis-report/. Accessed November 2013.

35. Edenhofer, O., Knopf, B., Barker, T., Baumstark, L., Bellevrat, E., Chateau, B., Criqui, P., Isaac, M., Kitous, A., Kypreos, S., Leimbach, M., Lessmann, K., Magné, B., Scrieciu, S., Turton, H., van Vuuren, D. P. (2010). The economics of low stabilization: model comparison of mitigation strategies and costs. The Energy Journal, 31, Special Issue 1: The economics of low stabilization, 1-38.

36. Edenhofer, O., Lessmann, K., Kemfert, C., Grubb, M., Koehler, J. (2006). Induced technological change: exploring its implications for the economics of atmospheric stabilization: synthesis report from the innovation modeling comparison project. The Energy Journal, 27, Special Issue 1: Endogenous Technological Change and the Economics of Atmospheric Stabilization, 57-107.

37. Filar, J. A., Haurie, A. (Eds.) (2010). Uncertainty and environmental decision making, Berlin, Germany: Springer, 338 p. 
38. Fischer, C., Newell, R.G. (2008). Environmental and technology policies for climate mitigation. Journal of Environmental Economics and Management, 55(2), 142-162.

39. Fischer, C., Preonas, L. (2010). Combining policies for renewable energy: is the whole less than the sum of its parts? International Review of Environmental and Resource Economics, 4(1), 51-92.

40. FONDDRI (2009). Carbon-constrained scenarios, joint research project, 89 p.

http://www.iddri.org/L'iddri/Fondation/FONDDRI_Full_Report_Carbon _constrained_scenarios_EN.pdf. Accessed November 2013.

41. Gerlagh, R., Kverndokk, S., Rosendahl, K. E. (2009). Optimal timing of climate change policy: interaction between carbon taxes and innovation externalities. Journal of Environmental and Resource Economics, 43(3), 369-390.

42. Goulder, L.H., Parry, I.W.H., Williams, R.C., Burtraw, D. (1999). The cost-effectiveness of alternative instruments for environmental protection in a second-best setting. Journal of Public Economics, 72, 329-360.

43. Greenpeace (2005). Energy revolution: A sustainable pathway to a clean energy future for Europe. A European energy scenario for EU-25. $32 \mathrm{p}$.

http://www.greenpeace.org/eu-unit/Global/eu-unit/reportsbriefings/2009/3/energy-revolution-a-sustaina.pdf. Accessed November 2013.

44. Greenpeace (2008). Energy revolution: A sustainable global energy outlook. 211 p.

http://www.energyblueprint.info/fileadmin/media/documents/energy_re volution2009.pdf. Accessed November 2013.

45. Guesnerie, R., Stern, N. (2012). Introduction to the special issue on managing climate change. Journal of Public Economic Theory, 14(2), 189-196.

46. Gurney, A., Ahammad, H., Ford, M. (2009). The economics of greenhouse gas mitigation: Insights from illustrative global abatement scenarios modelling. Energy Economics, 31(S2), S174-S186.

47. Haurie, A., Tavoni, M., van der Zwaan, B. C. C. (2012). Modeling uncertainty and the economics of climate change: recommendations for 
robust energy policy. Environmental Modeling \& Assessment, 17(1-2), $1-5$.

48. Hourcade, J.-C., Ghersi, F. (2009). Interpreting environmental policy cost measures. In R. Gerlagh, V. Bosetti, S. Schleicher (Eds.), Modeling Sustainable Development (pp. 62-83). Cheltenham, UK: Edward Elgar.

49. Hourcade, J.-C., Jaccard, M., Bataille, C., Ghersi, F. (2006). Hybrid modeling: new answers to old challenges. The Energy Journal, 27, Special Issue 2: Hybrid modeling of energy-environment policies: reconciling bottom-up and top-down, 1-12.

50. INFORSE (2008). Vision for a sustainable energy development for EU27, 2000-2050, A European vision based on INFORSE's Sustainable Energy Vision. 11 p. http://www.inforse.org/europe/pdfs/EU27-vision-note.pdf. Accessed November 2013.

51. Interagency Working Group on Social Cost of Carbon (2010). Appendix $15 \mathrm{~A}$. Social cost of carbon for regulatory impact analysis under Executive Order 12866. In U.S. Department of Energy (Ed.), Final rule technical support document: Energy efficiency program for commercial and industrial equipment: Small electric motors. Washington, DC: U.S. Department of Energy.

52. IPCC (2001). Climate change 2001: Mitigation: Contribution of Working Group III to the third assessment report of the Intergovernmental Panel on Climate Change. B. Metz, O. R. Davidson, R. Swart, J. Pan (Eds.), Cambridge, UK: Cambridge University Press.

53. IPCC (2007). Climate change 2007: Mitigation of climate change: Contribution of Working Group III to the fourth assessment report of the Intergovernmental Panel on Climate Change. B. Metz, O. R.

Davidson, P. R. Bosch, R. Dave, L.A. Meyer (Eds.), Cambridge, UK: Cambridge University Press, $851 \mathrm{p}$.

54. Jaccard, M., Rivers, N., (2007). Heterogeneous capital stocks and the optimal timing for $\mathrm{CO}_{2}$ abatement. Resource and Energy Economics, 29(1), 1-16.

55. Jaffe, A. B., Newell, R. G., Stavins, R. N. (2005). A tale of two market failures: Technology and environmental policy. Ecological Economics, 54(2-3), 164-174.

56. Jaffe, A. B., Stavins, R. N. (1994). The energy-efficiency gap: what does it mean? Energy Policy, 22(10), 804-810. 
57. Kitous, A., Criqui, P., Bellevrat, E., Chateau, B. (2010). Transformation patterns of the worldwide energy system. Scenarios for the century with the POLES model. The Energy Journal, 31, Special Issue 1: The economics of low stabilization, 49-82.

58. Knopf, B., Edenhofer, O., Flachsland, C., Kok, M. T. J., Lotze-Campen, H., Luderer, G., Popp, A., van Vuuren, D. P. (2010). Managing the lowcarbon transition. From model results to policies. The Energy Journal, 31, Special Issue 1: The economics of low stabilization, 223-245.

59. Kopp, R. E., Golub, A., Keohane, N. O., Onda, C. (2012). The influence of the specification of climate change damages on the social cost of carbon. Economics: The Open-Access, Open-Assessment E-Journal, 6, $40 \mathrm{p}$.

60. Kopp, R. E., Mignone, B. K. (2012). The U.S. government's social cost of carbon estimates after their first two years: pathways for improvement. Economics: The Open-Access, Open-Assessment EJournal, 6, $41 \mathrm{p}$.

61. Kopp, R. E., Tol, R., Waldhoff, S. (2012). The social cost of carbon. Economics: The Open-Access, Open-Assessment E-Journal, 6, 1 p. http://www.economics-ejournal.org/special-areas/special-issues/thesocial-cost-of-carbon. Accessed October 2013.

62. Kretschmer, B., Narita, D., Peterson, S. (2009). The economic effects of the EU biofuel target. Energy Economics, 31(S2), S285-S294.

63. Lecocq F., Hourcade J.-C., Ha Duong, M. (1998). Decision making under uncertainty and inertia constraints: Sectoral implications of the when flexibility. Energy Economics, 20(5-6), 539-555.

64. Lecuyer, O., Bibas, R. (2012). Combining climate and energy policies. Synergies or antagonism? FEEM Nota di Lavoro, 98-2011, 19 p. http://www.feem.it/userfiles/attach/2012117914334NDL2011-098.pdf. Accessed November 2013.

65. Lecuyer, O., Quirion, P. (2013). Can uncertainty justify overlapping policy instruments to mitigate emissions? Ecological Economics, 93, 177-191.

66. Lipsey, R. G., Lancaster, K. (1956). The general theory of second best. The Review of Economic Studies, 24(1), 11-32.

67. Marten, A. L., Kopp, R. E., Shouse, K. C., Griffiths, C. W., Hodson, E. L., Kopits, E., Mignone, B. K., Moore, C., Newbold, S. C., Waldhoff, S., Wolverton, A. (2013). Improving the assessment and valuation of 
climate change impacts for policy and regulatory analysis. Climatic Change, 117(3), 433-438.

68. Moyer, E. J., Woolley, M. D., Glotter, M., Weisbach, D. A. (2013). Climate impacts on economic growth as drivers of uncertainty in the social cost of carbon. Center for Robust Decision Making on Climate and Energy Policy Working Paper, 13-02, 25 p.

69. Negawatt (2006). Scénario négaWatt 2006, pour un avenir énergétique sobre, efficace et renouvelable. $15 \mathrm{p}$.

http://www.negawatt.org/telechargement/Scenario\%20nW2006\%20Synt hese\%20v1.0.2.pdf. Accessed November 2013.

70. Nordhaus, W. D. (1992). The 'DICE' model: Background and structure of a dynamic integrated climate-economy model of the economics of global warming. Cowles Foundation Discussion Papers, 1009, 103 p.

71. Nordhaus, W. D. (2007). A review of the Stern review on the economics of climate change. Journal of Economic Literature, 45(3), 686-702.

72. Nordhaus, W. D. (2012). Economic policy in the face of severe tail events. Journal of Public Economic Theory, 14(2), 197-219.

73. OECD (2011). Interactions between emission trading systems and other overlapping policy instruments. General Distribution Document, Environment Directorate, OECD, Paris, $14 \mathrm{p}$.

http://www.oecd.org/env/toolsevaluation/Interactions\%20between \%20Emission\%20Trading\%20Syste ms\%20and\%200ther\%200verlapping\%20Policy\%20Instruments.pdf.

Accessed November 2013.

74. Oikonomou, V., Jepma, C. J. (2008). A framework on interactions of climate and energy policy instruments. Mitigation and Adaptation Strategies for Global Change, 13(2), 131-156.

75. Pindyck, R. S. (2011). Modeling the impact of warming in climate change economics. MIT Sloan School Working Paper, 4769-10, 32 p.

76. Pindyck, R. S. (2013). Climate change policy: What do the models tell us? National Bureau of Economic Research Working Paper, 19244, 21 p.

77. Pycroft, J., Vergano, L., Hope, C. W., Paci, D., Ciscar. J. C. (2011). A tale of tails: Uncertainty and the social cost of carbon dioxide. Economics: The Open-Access, Open-Assessment E-Journal, 5, 29 p.

78. Radanne, P. (2004). La division par 4 des émissions de dioxyde de carbone en France d'ici 2050. Report to the Mission Interministérielle 
de l'Effet de Serre, $36 \mathrm{p}$.

http://www.developpement-durable.gouv.fr/IMG/ecologie/pdf/Facteur4-

franc_BAT.pdf. Accessed November 2013.

79. Rao, S., Riahi, K., Stehfest, E., van Vuuren, D. P., Cheolhung, C., den Elzen, M., Isaac, M., van Vliet, J. (2008). IMAGE and MESSAGE

scenarios limiting GHG concentration to low levels. IIASA report IR-

08-020, Laxenburg, 57 p.

http://www.iiasa.ac.at/Admin/PUB/Documents/IR-08-020.pdf. Accessed November 2013.

80. Ravetz, J. R. (1997). Integrated environmental assessment forum:

Developing guidelines for "Good Practice". ULYSSES Working Paper, 97-1, 45 p.

81. Schneider, S. H. (1997). Integrated assessment modeling of global climate change: Transparent rational tool for policy making or opaque screen hiding value-laden assumptions? Environmental Modeling \& Assessment, 2(4), 229-249.

82. Stern, N. (2007). The economics of climate change: The Stern review. Cambridge, UK: Cambridge University Press.

83. Stern, N. (2013). The structure of economic modeling of the potential impacts of climate change: Grafting gross underestimation of risk onto already narrow science models. Journal of Economic Literature, 51(3), 838-859.

84. Tinbergen, J. (1952). On the theory of economic policy. Amsterdam, Netherlands: North Holland.

85. Tol, R. S. J. (2009). The feasibility of low concentration targets: An application of FUND. Energy Economics, 31(S2), S121-S130.

86. Van der Ploeg, F., Withagen, C. (2012). Is there really a green paradox? Journal of Environmental Economics and Management, 64(3), 342-363.

87. Vogt-Schilb, A., Hallegatte, S. (2011). When starting with the most expensive option makes sense: Use and misuse of marginal abatement cost curves. World Bank Policy Research Working Paper Series, 5803, $21 \mathrm{p}$.

88. Vogt-Schilb, A., Meunier, G., Hallegatte, S. (2012). How inertia and limited potentials affect the timing of sectoral abatements in optimal climate policy. World Bank Policy Research Working Paper Series, $6154,22 \mathrm{p}$. 
89. Weitzman, M. L. (2012). GHG targets as insurance against catastrophic climate damages. Journal of Public Economic Theory, 14(2), 221-244.

90. Yohe, G., Hope, C. (2013). Some thoughts on the value added from a new round of climate change damage estimates. Climatic Change, $117(3), 451-465$.

91. ZCB (2007). Zero Carbon Britain. An alternative energy strategy. Llwyngwern, UK: CAT Publications.

http://zerocarbonbritain.com/index.php/component/k2/item/64?Itemid=1 13. Accessed November 2013.

92. ZCB (2010). Zero Carbon Britain 2030, A new energy strategy. Llwyngwern, UK: CAT Publications. http://zerocarbonbritain.com/index.php/component/k2/item/62?Itemid=1 13. Accessed November 2013. 